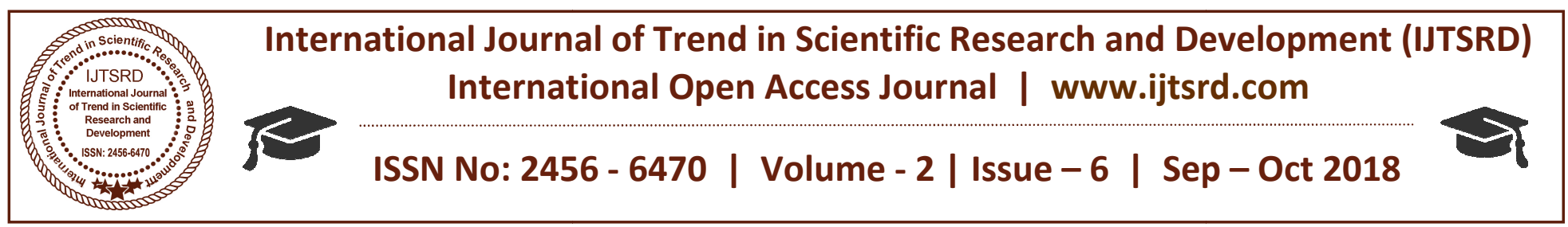

\title{
Essence of Business 4.0
}

\author{
Matthew N. O. Sadiku' ${ }^{1}$, Nana K. Ampah ${ }^{2}$, Sarhan M. Musa ${ }^{1}$ \\ ${ }^{1}$ Professor, ${ }^{2}$ Adjunct Faculty \\ ${ }^{1}$ Roy G. Perry College of Engineering, Prairie View A\&M University, Prairie View, Texas \\ ${ }^{2}$ Lone Star College Kingwood, Houston, Texas
}

\begin{abstract}
Industry 4.0 technologies aid manufacturers in monitoring production processes and making effective decisions. In a similar way, Business 4.0 technologies can help sales, marketing and customer service, drive profits and productivity, and help the companies stay competitive. It requires a new way of thinking and involving the employees, customers, and partners. This paper provides a brief introduction to Business 4.0.
\end{abstract}

Keyword: business 4.0, industry 4.0

\section{INTRODUCTION}

Information technology has radically transformed the very essence of large businesses around the world. Companies in every industry sector all over the world are planning to increase digitization of products and processes. Digitalization involves using technologies, products, and data to maximize revenue and improve business models.

Digitalization has been penetrating the market with digital products, digital processes, digital services, and digital solutions [1]. Digital transformation will only take place if top management makes Industry 4.0 a top priority. Many companies are transforming their businesses using Internet of things (IoT) technology.

The foundational aspects of a digital culture include agility in decision making, increased collaboration, willingness to experiment, and continuous learning and adaptation. The greatest challenge of industrial leaders is people, not technology. Anytime, anywhere learning and development organizations require an agile workforce that can continuously learn new skills and apply their learning to challenges [2].
A storm of technologies (Internet of things, cloud computing, artificial intelligence, automation/ robotics, big data and analytics) is transforming industry after industry. These technologies will fundamentally change individual companies and transform market dynamics across a whole range of industries. Digital to its core, Business 4.0 consists of technologies such as automation and artificial intelligence. Whether large or small, all companies must respond to the digital challenge now. As companies move forward in their Business 4.0 journey, they leverage digital technologies to drive their growth.

\section{EMERGENCY OF INDUSTRY 4.0}

Recently industrial powers like Germany, USA, UK, and China initiated the concept of Industry 4.0. The term 'Industry 4.0' stands for the fourth industrial revolution or Industrial Internet of things (IIOT). Industry 4.0 is driven by digitization and integration of vertical and horizontal value chains. Industry 4.0 is the current gradual industrial transformation with automation, cloud computing, cyber-physical systems, robots, and industrial IoT to realize smart industry and manufacturing [3]. It utilizes cyber-physical systems, in which machines communicate efficiently with each other.

Industry 4.0 has moved from talk to action since it is now at the heart of strategic and research agenda of many companies. No company can afford to ignore the fundamental changes that Industry 4.0 will bring. Industry 4.0 is helping companies optimize customer relationships. It has implications for the nature of how a company organizes itself and its delivery model. Data analytics and digital trust lie at the heart of the fourth industrial revolution. Data and data analytics provide tools for decision making. 


\section{EMERGENCY OF BUSINESS 4.0}

The convergence of digital, physical, and biological technologies is transforming the world. This new world will be shaped by the companies that can best harness Business 4.0. Being able to employ modern technologies such as Internet of things, cloud computing, artificial intelligence, automation, and big data and analytics are the indicators of a Business 4.0 company. This shift towards Business 4.0 will enable companies to evolve from a traditional productionfocused model to an information-based approach. This will benefit both the customer and the company itself [4].

A major principle of industry 4.0 is to shift the business models based on mass productions within manufacturing to mass customization. In the future, industrial businesses will be adopting new business models that will connect their factories, machinery, and warehousing facilities as cyber physical systems [5].

Business 4.0 is mainly using analytics to respond to individual transactions through customization. Business 4.0 can increase automation. Activities like data entry, reporting, and meeting preparation can now be performed by the system. This frees up your time to do the things. The health and safety of human workers in dangerous working environments could be improved dramatically.

\section{CHALLENGES}

The absence of a digital culture and the right training for employees is a top challenge facing companies. The basic aspects of a digital culture consists agility in decision making, increased collaboration, willingness to experiment, and continuous learning and adaptation [6]. Without the appropriate digital culture, the best talent will hesitate to stay. Lack of skills or competencies in the company's workforce is a challenge. There is also a challenge to build digital trust, which is based on three pillars: transparency, legitimacy and effectiveness.

\section{CONCLUSION}

Business 4.0 will definitely make companies function differently than they did in the past. Advanced implementation of Business 4.0 will become a qualifier to compete. Organizations that proactively harness agile talent and align the growth aspirations of their employees are poised to lead the Business 4.0 transformation. By embracing these new technologies, salespeople, marketers and customer service professionals can become more responsive and competitive [7].

\section{REFERENCES}

1. J. Mäkiö1, A. Miroliubo, and V. Zhgun, "Digitalization - quo vadis," SHS Web of Conferences, 2018.

2. "Industry 4.0: Building the digital enterprise," https://www.pwc.com/gx/en/industries/industries4.0/landing-page/industry-4.0-building-yourdigital-enterprise-april-2016.pdf

3. M. N. O. Sadiku, S. M. Musa, and O. M. Musa,"The essence of Industry 4.0," Invention Journal of Research Technology in Engineering and Management, vol. 2, no. 9, September 2018, pp. 64-67.

4. "4 ways best-in-class companies are embracing Business 4.0," http://tcssummiteurope.com/4-ways-best-in-classcompanies-are-embracing-business-4-0/

5. M. J. Too, "Industry 4.0 as smart enabler for innovative business models," https://brage.bibsys.no/xmlui/bitstream/handle/11 250/2452846/Toor\%2C\%20Junaid.pdf? sequence $=$ 1

6. "Reimagining talent management for Business 4.0,"

https://www.tcs.com/content/dam/tcs/pdf/Industrie s/hitech/abstract/Reimagining\%20Talent\%20Man agement\%20for\%20Business\%204.0_200318.pdf

7. N. Davies, "Business 4.0 - how technology is changing the business of manufacturing," September 2017, https://www.salesi.com/business-4-0-technology-changingbusiness-manufacturing 